\title{
Peningkatan Pengetahuan Karyawan Rumah Sakit Umum Daerah Labuang Baji Makassar Pasca Pelatihan Pelayanan Prima
}

\author{
Fridawaty Rivai*, Syahrir A. Pasinringi, Noer Bahry Noor, Nur Arifah, Adelia U. Ady Mangilep \\ Departemen Manajemen Rumah Sakit Fakultas Kesehatan Masyarakat Universitas Hasanuddin* \\ fridarivai@yahoo.com*
}

\begin{abstract}
Abstrak
Permasalahan yang dialami oleh Rumah Sakit Umum Daerah (RSUD) Labuang Baji Makassar sebagai sebuah rumah sakit yang terbilang baru terbentuk dengan tenaga kesehatan khususnya perawat sebagian besar adalah fresh graduate sehingga pengalaman dan keterampilan dalam melayani pasien masih rendah. Dari data yang diperoleh, komplain terhadap pelayanan RSUD Labuang Baji Makassar yakni keramahan petugas dengan persentase $24 \%$ dan pelayanan yang lambat dengan total $21 \%$. Pelayanan yang berkualitas merupakan harapan semua pasien yang menerima jasa pelayanan kesehatan. Meski demikian, tidak semua rumah sakit mampu memberikan pelayanan yang diinginkan. Hal ini disebabkan karena pelayanan kesehatan yang berkualitas hanya dapat diberikan oleh tenaga yang professional yang memiliki pengetahuan dan kemampuan yang baik, sehingga pasien dapat merasa nyaman. Metode pelatihan pelayanan prima yang dilaksanakan melibatkan mitra secara aktif sehingga nantinya diharapkan nantinya pelatihan ini akan sebagai training of trainer (TOT) buat para peserta yang diharapkan nantinya ketika mereka menyelesaikan pelatihan dapat menjadi pemateri untuk melatih staf RSUD Labuang Baji lainnya. Pelatihan ini akan dilakukan dengan menerapkan metode ceramah, tanya jawab, diskusi kelompok, permainan, simulasi dan presentase kelompok. Untuk melihat pengaruh dari pelatihan, maka dilakukan pre test and post test one group dengan jumlah peserta sebanyak 16 orang. Hasil menunjukkan bahwa terjadi peningkatan pengetahuan pada peserta pelayanan prima pada saat sebelum pelatihan dan setelah pelatihan. Sebelum pelatihan tingkat pengetahuan hanya 9 orang $(56,3 \%)$ yang tinggi, dan setelah pelatihan meningkat menjadi 93,8 \% atau sebanyak 15 orang. Berdasarkan hasil analisis pada pelatihan pelayanan prima terjadi peningkatan pengetahuan peserta mengenai konsep mutu layanan rumah sakit, kepuasan dan loyalitas pelanggan, sikap dan penampilan pelayanan prima, komunikasi verbal dan non verbal dalam pelayanan kesehatan, membangun kecerdasan emosi melayani pelanggan, menangani keluhan pelanggan serta metode pengukuran kepuasan. Dengan adanya pelatihan pelayanan prima diharapkan agar para peserta pelatihan dapat mengaplikasikan pengetahuan yang telah didapatkan agar memberikan pelayanan yang memuaskan bagi pasien.
\end{abstract}

Kata Kunci: Karyawan; pelatihan; pelayanan prima; pengetahuan; rumah sakit.

\begin{abstract}
The problem occured in Labuang Baji Makassar Hospital as a newly formed hospital with health workers, especially nurses mostly comes from fresh graduates so their experience and skills of serving patients are still low. From the data that we obtained, complaints against the services of Labuang Baji Makassar Hospital are staff friendliness only reached $24 \%$ and slow service with a total of 21\%. Quality services are the expectation of all patients who received health service. Even so, not all the hospital able to offer a service that desired. This is because of good quality health services can only be administered by the professional workers who have good knowledge and skills, so the patient can feel comfortable. The excellent service training method was involved the trainee partners. So, this training can be expected to improve the trainee become trainers to train other Labuang Baji Hospital staff. This training will be conducted by applying discourse methods, question and answer, group discussions, games, simulations and group presentation. One group pre-test and post-test was conducted with 16 participants to see the impact from the training. The results show that there awas an increased knowledge of the excellent service participants before the training and after the training. Before the training the level of knowledge of 9 people (56.3\%) who were in high level, and after training increased to $93.8 \%$ or as many as 15 people. Based on the results of the analysis on excellent service training there was an increased in participants' knowledge about the concept of hospital services, customer satisfaction and loyalty, attitude and appearance of excellent service, verbal and nonverbal communication in health services, intelligence development, transportation assistance, satisfaction assistance. With the existence of excellent service training, it is expected that the training participants can apply the knowledge they have obtained in order to provide satisfying services for patients.
\end{abstract}


Jurnal Tepat (Teknologi Terapan Untuk Pengabdian Masyarakat), Volume 2, Nomor 1, Tahun 2019

Keywords: Employee; excellent service; hospital; knowledge; training.

\section{Pendahuluan}

Saat ini, rumah sakit berada dalam iklim persaingan yang sangat ketat. Masyarakat sebagai pelanggan berada dalam posisi yang lebih kuat karena semakin banyak pilihan rumah sakit yang dapat melayaninya. Pada saat yang bersamaan, masyarakat juga semakin kritis terhadap pelayanan kesehatan. Dalam kondisi seperti ini, agar tetap dapat eksis melayani pelanggannya, rumah sakit harus memiliki sumberdaya manusia yang berkualitas. Salah satu aspeknya adalah kemauan dan kemampuan dalam memberikan pelayanan yang prima. Bukan pandangan aneh lagi apabila seseorang berada di rumah sakit pasti yang terlintas di pikirannya adalah rasa takut dan bosan terhadap suasana rumah sakit, sering ditemui rumah sakit memberikan pelayanan yang tidak memuaskan kepada pelanggan, khususnya pada tenaga medis yang memberikan pelayanan kurang memuaskan dan akhirnya berdampak pelanggan tidak ingin berobat lagi di rumah sakit tersebut. Jika kita berbicara kepuasan pelayanan tentunya kesuksesan tidak hanya ditentukan oleh bagian customers services, melainkan peran serta seluruh departemen di rumah sakit dituntut juga untuk menerapkan pelayanan prima.

Sugesti inilah yang menjadi tugas bagi para pengembang jasa pelayanan kesehatan untuk menghilangkanya jauh-jauh dari pola fikir masyarakat dan bagaimana caranya bisa meciptakan suasana aman dan nyaman keseluruh pengunjung rumah sakit terutama para pelanggan karena akan memberikan efek yang luar biasa pada pelanggan. Mereka pada dasarnya tidak hanya ingin berobat namun juga ingin diperhatikan, di hormati dan disanjung. Jika semua lini di rumah sakit tersebut mampu memberikan service excellent di rumah sakit yang bagus efeknya tidak hanya kepuasan pelanggan namun omset yang didapat juga akan meningkat.

Pelayanan prima adalah perbuatan atau tindakan yang memberikan kepada pelanggan apa (yang lebih daripada) yang memang diharapkan pada saat mereka membutuhkan dengan cara yang diinginkan dan lebih baik daripada penawaran sejenis lainnya. Di era globalisasi ini, pelayanan prima dengan sendirinya menjadi elemen utama bagi kemampuan sebuah unit kesehatan untuk bertahan. Sayangnya, manajemen dan profesionalisme unit-unit kesehatan masih sangat jauh dari memuaskan, sehingga pelayanan kesehatan yang memuaskan menjadi sesuatu yang sangat mahal di negara ini. Hal ini terutama sangat dirasakan pada organisasi pelayanan pemerintah seperti RSUD, yang mana kondisi dan mutu pelayanan masih sangat jauh dari standar dan harapan masyarakat.

Permasalahan tersebut juga dialami oleh Rumah Sakit Umum Daerah (RSUD) Labuang Baji Makassar. Sebagai sebuah rumah sakit yang terbilang baru terbentuk dengan tenaga kesehatan khususnya perawat sebagian besar adalah fresh graduate sehingga pengalaman dan keterampilan dalam melayani pasien masih rendah. RSUD Labuang Baji diharapkan kedepannya dapat menjadi model bagi rumah sakit pemerintah lainnya dalam memberikan pelayanan yang prima dituntut untuk dapat memperbaiki mutu layanannya. Berdasarkan data sekunder yang diperoleh dari RSUD Labuang Baji dapat dilihat bahwa masih terdapat beberapa komplain terkait mutu pelayanan RSUD Labuang Baji khususnya yang menyangkut pelayanan prima. Rekapan komplain pasien selama tahun 2017 di RSUD Labuang Baji dapat dilihat pada tabel berikut: 
Tabel 1. Rekapan komplain pasien terhadap pelayanan RSUD Labuang Baji, Tahun 2017

\begin{tabular}{|l|l|c|c|}
\hline No & \multicolumn{1}{|c|}{ Komplain } & Jumlah & Persentase \\
\hline 1. & $\begin{array}{l}\text { Fasilitas medik dan non medik yang belum memadai } \\
\text { dan banyak rusak }\end{array}$ & 84 & 55 \\
\hline 2. & Dokter yang jarang visite dan kurang ramah & 37 & 24 \\
\hline 3. & $\begin{array}{l}\text { Sistem pelayanan apotik yang lama dan ketersediaan } \\
\text { obat }\end{array}$ & 20 & 13 \\
\hline 4. & Pelayanan Poliklinik lambat & 10 & 7 \\
\hline 5. & Pelayanan UGD Lambat & 2 & 1 \\
\hline
\end{tabular}

Sumber: Data RSUD Labuang Baji, 2015

Tabel diatas memperlihatkan bahwa komplain terhadap pelayanan RSUD Labuang Baji terbanyak berkaitan dengan mutu pelayanan seperti keramahan petugas dan pelayanan yang lambat. Hasil penelitian yang dilakukan pada tahun 2017 terhadap 272 pasien di RSUD Labuang Baji memperlihatkan hasil bahwa terdapat hubungan signifikan tingkat kepuasan pasien terhadap pelayanan RSUD Labuang Baji dengan Attitudes and Behaviors pemberi pelayanan ( $\mathrm{p}=0,004)$ (Wenty, 2014). Studi lain yang dilakukan pada tahun 2016 tentang kepuasan pasien BPJS memperlihatkan bahwa terdapat hubungan kuat antara kemampuan komunikasi perawat dengan kepuasan pasien (Ameliyah, 2105).

Berdasarkan beberapa masalah tersebut diatas dapat disimpulkan bahwa mutu pelayanan di RSUD Labuang Baji khususnya dari segi pelayanan komunikasi, sikap dan perilaku petugas masih harus ditingkatkan karena hal tersebut sangat erat kaitannya dengan peningkatan kepuasan pasien.

\section{Latar Belakang Teori}

Endarini (2001) dalam Hadjam (2001) mendefinisikan pelayanan prima dalam konteks pelayanan rumah sakit berarti pelayanan yang diberikan kepada pasien yang berdasarkan standar kualitas untuk memenuhi kebutuhan dan keinginan pasien sehingga pasien dapat memperoleh kepuasan yang akhirnya dapat meningkatkan kepercayaannya kepada rumah sakit. Sunartini (2000) menjelaskan pelayanan prima di Rumah Sakit melibatkan seluruh karyawan dari manajer puncak sampai ke pekarya. Para profesi yang meliputi berbagai bidang kedokteran atau kesehatan merupakan ujung tombak pelayanan di Rumah Sakit, yang tidak hanya dituntut profesional akan tetapi juga diharapkan peran serta aktifnya dalam manajemen Rumah Sakit termasuk manajemen mutu (Hadjam, 2001).

Pelayanan prima adalah pelayanan yang tidak hanya memenuhi kebutuhan dan harapan pelanggan, namun melebihi apa yang menjadi harapan pelanggan, secara terkontrol dan berkesinambungan. Konsep pelayanan prima terdiri atas:

(1)Pelayanan yang memuaskan pelanggan

(2)Pelayanan diatas standar

(3)Pelayanan yang sesuai Standard Operational Procedure

(4)Pelayanan yang terbaik yang bisa diberikan

(5)Pelayanan yang selalu mempertinggi kepuasan pelanggan. 
Kualitas pelayanan di setiap institusi layanan kesehatan diharapkan dapat memenuhi kepuasan pasien sebagai penerima pelayanan kesehatan. Kepuasan pasien sendiri memiliki pengaruh terhadap peningkatan kualitas rumah sakit atau klinik tersebut (Shelton, 2000). Muttaqin (2008) menyatakan pelayanan berkualitas merupakan harapan semua pasien yang menerima jasa pelayanan kesehatan. Meski demikian, tidak semua rumah sakit mampu memberikan pelayanan yang diinginkan. Hal ini disebabkan karena pelayanan kesehatan yang berkualitas hanya dapat diberikan oleh tenaga yang professional yang memiliki pengetahuan dan kemampuan yang baik, sehingga pasien dapat merasa nyaman (Silalahi dan Novy, 2013). Pengetahuan dan kemampuan tenaga professional dapat ditingkatkan dengan memberikan pelatihan-pelatihan.

Pelatihan merupakan proses pembelajaran yang melibatkan perolehan keahlian, konsep, peraturan, atau sikap untuk meningkatkan kinerja karyawan (Simamora, 2004). Sedangkan Mangkuprawira (2004) mendefinisikan pelatihan adalah suatu proses mengajarkan pengetahuan dan keahlian serta sikap agar karyawan semakin terampil dan mampu melaksanakan tanggung jawabnya dengan semakin baik sesuai dengan standar.

\section{Metode}

Metode pelatihan pelayanan prima yang dilaksanakan melibatkan mitra secara aktif sehingga nantinya diharapkan nantinya pelatihan ini akan sebagai training of trainer (TOT) buat para peserta yang diharapkan nantinya ketika mereka menyelesaikan pelatihan dapat menjadi pemateri untuk melatih staf RSUD Labuang Baji lainnya. Pelatihan ini akan dilakukan dengan menerapkan metode ceramah, tanya jawab, diskusi kelompok, permainan, simulasi dan presentase kelompok. Untuk melihat pengaruh pelatihan pelayanan prima terhadap karyawan di RSUD Labuang Baji, maka dilakukan pre test and post test one group Sesuai alur pelatihan pada gambar 1. Pelatihan ini dilakukan pada bulan Juli tahun 2018. Peserta pelatihan adalah pegawai frontliner RSUD Labuang Baji yang terdiri dari dokter, perawat, apoteker, dan petugas administrasi. Jumlah peserta dalam pelatihan ini yakni sebanyak 16 orang. Kemudian, hasil dari pre test and post test diolah dengan menggunakan aplikasi statistik dan kemudian disajikan dengan tabular presentation dalam bentuk tabel distribusi frekuensi dan diikuti naratif/textular presentation untuk membahas hasil serta pengaruh dari pelatihan pelayanan prima terhadap karyawan di RSUD Labuang Baji yang disajikan dalam tabel.

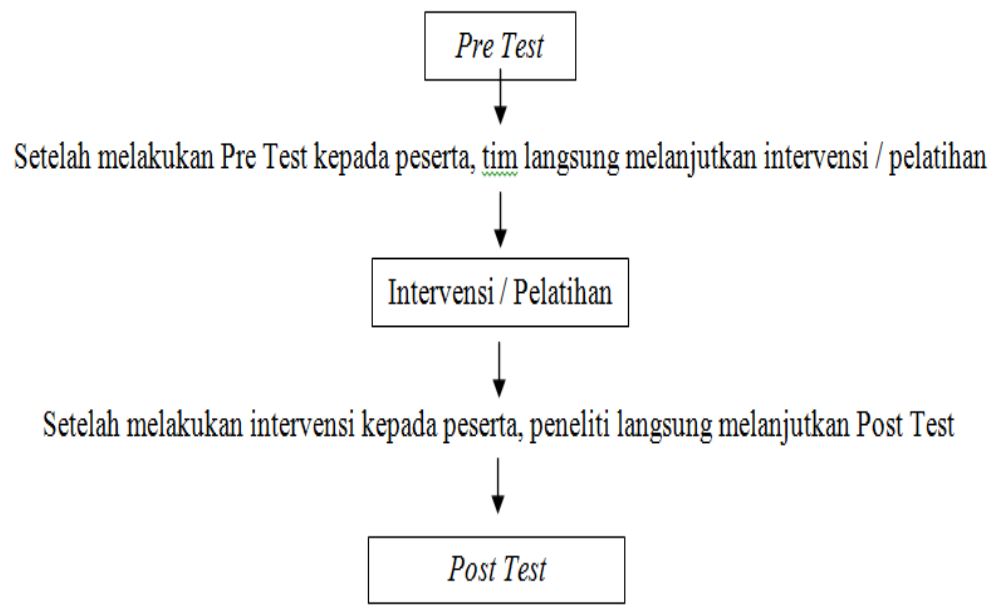

Gambar 1. Alur Pelatihan 


\section{Hasil dan Diskusi}

Pelatihan pelayanan prima bagi Karyawan RSUD Labuang Baji yang dilaksanakan di Fakultas Kesehatan Masyarakat ruangan K225 Fakultas Kesehatan Masyarakat Universitas Hasanuddin selama 3 hari yaitu pada tanggal 31 Agustus sampai 2 September 2018. Kegiatan ini merupakan salah satu upaya untuk meningkatkan kemampuan dan pengetahuan petugas kesehatan yang ada di rumah sakit dalam memberikan pelayanan kepada pasien dan masyarakat.

Berikut ini distribusi peserta pelayanan prima berdasarkan karakteristik:

Tabel 2. Distribusi Frekuensi Hasil Pre-Post Test Peserta Pelatihan Pelayanan Prima bagi Karyawan RSUD Labuang Baji Makassar Tahun 2018

\begin{tabular}{ccccc}
\hline \multirow{2}{*}{ Tingkat Pengetahuan } & \multicolumn{2}{c}{ Sebelum Pelatihan } & \multicolumn{2}{c}{ Setelah Pelatihan } \\
\cline { 2 - 5 } & $\mathbf{n}$ & $\mathbf{\%}$ & $\mathbf{n}$ & $\boldsymbol{\%}$ \\
\hline Baik & 9 & 56,3 & 15 & 93,8 \\
Kurang & 7 & 43,7 & 1 & 6,2 \\
\hline Total & $\mathbf{1 6}$ & $\mathbf{1 0 0}$ & $\mathbf{1 6}$ & $\mathbf{1 0 0}$ \\
\hline
\end{tabular}

Sumber : Data Primer, 2015

Tabel 2 menunjukkan bahwa terjadi peningkatan pengetahuan pada peserta pelayanan prima pada saat sebelum pelatihan dan setelah pelatihan. Sebelum pelatihan tingkat pengetahuan hanya 9 orang $(56,3 \%)$ yang tinggi, dan setelah pelatihan meningkat menjadi 93,8\% atau sebanyak 15 orang. Dapat dikatakan bahwa materi-materi yang diberikan selama pelatihan, membuat pengetahuan terkait pemberian pelayanan pada karyawan RSUD Labuang Baji meningkat.

Melalui materi konsep mutu layanan rumah sakit serta materi kepuasan dan loyalitas pelanggan, peserta pelatihan dapat mengetahui bagaimana kedua hal ini akan saling mempengaruhi. Azwar (2010) menyatakan mutu pelayanan kesehatan segala sesuatu yang merujuk pada kesempurnaan penampilan penyelenggaraan pelayanan kesehatan yang satu pihak dapat memuaskan para pemakai jasa pelayanan kesehatan dan di satu pihak lainnya tata cara penyelenggaraan pelayanan kesehatannya telah sesuai dengan kode etik serta standar yang telah ditetapkan. Materi sikap dan penampilan pelayanan prima serta etiket pelayanan prima dapat mempengaruhi bagaimana karyawan RSUD Labuang Baji untuk pemberian pelayanan kepada pasien. Pelayanan yang diberikan haruslah benar-benar memuaskan bahkan harus bisa membuat pelanggan merasa terpuaskan dan lebih dihargai, karena jika pelayanan yang didapatkan baik maka pelanggan tidak hanya sekali menggunakan jasa pelayanan rumah sakit, bahkan pelanggan juga akan menyampaikan kepuasannya kepada orang-orang di sekitarnya. Masyarakat akan lebih percaya terhadap orang yang sudah memiliki pengalaman langsung dibandingkan iklan atau janji-janji melalui media apapun.

Materi terkait komunikasi verbal dan non verbal dalam pelayanan kesehatan serta membangun kecerdasan emosi melayani pelanggan dapat meningkatkan pengetahuan peserta pelatihan untuk mampu mengerti terkait keinginan pasien. Hal ini kemudian yang akan memberikan pengaruh terhadap respon yang akan diberikan oleh petugas, yang terasa tepat dan benar oleh pasien karena pesan melalui verbal maupun non verbal akan sesuai dengan kebutuhan pasien. Melalui materi menangani keluhan pelanggan, pengetahuan petugas dalam hal bagaimana menyikapi keluhan pasien, baik itu dari ucapan, ekspresi, maupun tindakan menjadi meningkat. Sehingga, 
keluhan dari pelanggan dapat diselesaikan dengan baik. Materi terakhir terkait metode pengukuran kepuasan pelanggan. Jika berbicara kepuasan pelayanan tentunya kesuksesan tidak hanya ditentukan oleh bagian customers services, melainkan peran serta seluruh departemen di rumah sakit dituntut juga untuk menerapkan pelayanan prima. Sangat penting untuk mengetahui bagaimana pengukuran terkait kepuasan. Karena melalui hasil dari pengukuran ini, rumah sakit dapat melakukan evaluasi terkait pelayanan atau aspek yang kemudian dapat dilakukan perbaikan atau peningkatan pelayanan pada aspek tertentu. Dalam sistem kualitas modern pengukuran performa kualitas terbagi kedalam 4 dimensi, salah satunya dengan mengukur kepuasan pelanggan dan karakteristik yang diinginkan (Gaspersz, 2005).

\section{Kesimpulan}

Berdasarkan hasil analisis pada pelatihan pelayanan prima terjadi peningkatan pengetahuan peserta mengenai konsep mutu layanan rumah sakit, kepuasan dan loyalitas pelanggan, sikap dan penampilan pelayanan prima, komunikasi verbal dan non verbal dalam pelayanan kesehatan, membangun kecerdasan emosi melayani pelanggan, menangani keluhan pelanggan serta metode pengukuran kepuasan. Dengan adanya pelatihan pelayanan prima diharapkan agar para peserta pelatihan dapat mengaplikasikan pengetahuan yang telah didapatkan agar memberikan pelayanan yang memuaskan bagi pasien.

\section{Ucapan Terima Kasih}

Tim peneliti mengucapkan terimakasih kepada pemateri dan juga peserta pelatihan pelayanan prima dalam hal ini adalah petugas yang berasal dari RSUD Labuang Baji serta kepada LP2M Universitas Hasanuddin sebagai lembaga yang memfasilitasi pendanaan untuk kegiatan pengabdian masyarakat ini.

\section{Daftar Pustaka}

Ameliyah, Ayu Rezky. (2015). Analisis Hubungan antara Persepsi mutu pelayanan terhadap kepuasan pasien BPJS pada Instalasi Rawat inap RSUD Labuang Baji, Makassar. Skripsi FKM Unhas.

Azwar, A. (2010). Menjaga Mutu Pelayanan Kesehatan. Jakarta: Sinar Harapan.

Gaspersz, Vincent. (2005). Total Quality Management. Gramedia Pustaka Utama, Jakarta.

Hadjam, Noor Rochman. (2001). Efektivitas Pelayanan Prima sebagai Upaya Meningkatkan Pelayanan di Rumah Sakit (Perspektif Psikologi). Jurnal Psikologi, 2, 105-115.

Mangkuprawira (2004). Manajemen Sumber Daya Manusia Strategik. Jakarta: Ghalia IndonesiaShelton. (2000). Measuring and improving patient satisfaction. Maryland: AN Aspen Publication

Silalahi, Tiur Dame, dan Novy Daulima. (2013). Hubungan Tingkat Pengetahuan Perawat dengan Kualits Pelayanan Keperawatan: Kenyamanan pada Kasus Kegawatan Onkologi. FKM UI.

Simamora, Bilson (2004). Panduan Riset Perilaku Konsumen. Jakarta: Gramedia.

Wenty, Darmayanita. (2014). Analisis Pengaruh Kualitas Pelayanan dan Kepuasan Pasien terhadap Words of Mouth di Instalasi Rawat Inap RS Unhas. Tesis FKM Unhas. 